\title{
Femur başı avasküler nekrozunda serbest damarlı fibula grefti ile tedavi
}

\section{Treatment with free vascularized fibular grafting for avascular necrosis of the femoral head}

\author{
Kahraman Öztürk, Mehmet Baydar, Osman Orman
}

Sağlık Bilimleri Üniversitesi, Tıp Fakültesi Ortopedi ve Travmatoloji Anabilim Dalı, El Cerrahisi Kliniği, İstanbul

\begin{abstract}
Biyolojik bir rekonstrüksiyon olan serbest damarlı fibular greftlemenin ideal endikasyonu, çökme olmamış femur başı avasküler nekrozu (osteonekrozu) olan genç ve aktif hastalardır. Femur başı intraosseöz basıncının azaltılması ve nekrotik kemiğin çıkarılması ile birlikte serbest damarlı fibular greftleme, başın çökmesinin önlenmesinde veya en aza indirilmesinde etkilidir. Serbest damarlı fibula grefti uygulamasında amaç, canlı kortikal bir destek ile subkondral yüzeyi desteklemek ve femur başının yeniden damarlanması ile kanlanmasını artırmaktır. Femur başı osteonekrozu olan hastalarda damarlı fibula grefti kalça protez ihtiyacını ortadan kaldırmakta ya da geciktirmektedir.
\end{abstract}

Anahtar sözcülkler: avasküler nekroz; osteonekroz; femur başı; serbest damarlı fibula grefti; yeniden damarlanma
Free vascularized fibular grafting is a good biological reconstruction option for young and active patients with femoral head avascular necrosis (osteonecrosis) at pre-collapse stage. Free vascularized fibular grafting plays a significant role in preventing or minimizing development of femoral head collapse by decreasing the interosseous pressure and removal of the necrotic bone. It is believed that free vascularized fibular grafting provides support for chondral surface with a viable cortical bone, and improves the revascularization of the femoral head. In patients with osteonecrosis of the femoral head, vascularized fibula graft slows the course of the disease and delays or eliminates the need for hip prostheses.

Key words: avascular necrosis; osteonecrosis; femoral head; free vascularized fibular graft; revascularization ayatın erken evrelerini etkileyen femur başı avasküler nekrozunun (osteonekrozunun) doğal seyri, femur başında subkondral kemiğin kırılması, eklem kıkırdağının çökmesi ve kalçada dejeneratif artroz ile sonuçlanır. (Şekil 1). ${ }^{[1-3]}$ Tüm tedavi yaklaşımlarında amaç, femur başı osteonekrozunda kondral çökmeyi engelleyerek femur başı sferisitesini korumak veya endoproteze gidişi geciktirmektir. ${ }^{[1,4]}$ Çökme meydana gelmemiş femur başı osteonekroz tedavisinde ağırlık kısıtlaması ve gözlem; kor dekompresyon ve gerektiğinde greftleme; eklem dışı osteotomi ve yük taşıyan alanın değiştirilmesi; nekrotik kemiğin küretajı ve damarlı veya damarsız fibula grefti dâhil olmak üzere çeşitli tedavi yaklaşımları tanımlanmıştır. ${ }^{[1,2,5-7]}$

Femur başında çökme olmadan uygulanan serbest damarlı fibula grefti (SDFG) provokasyonla yeni kemik oluşumunu ve kıkırdak beslenmesini sağlayabilen biyolojik bir rekonstrüksiyondur. ${ }^{[2,4,5,8]}$ Fibular greftin biyolojik potansiyeli ve zengin kanlanması, greftin başa giden ucundaki periosteal kambiyum tabakası ve kortikal kemik ile osteonekrotik femur başının geriye kalan subkondral spongiyoz kemiği arasında kallus oluşumunun elde edilmesini sağlar. ${ }^{[9,10]}$ Damarlı fibula grefti femur başında çökme oluşmadan önce yapılır ve greft ile femur başı arasında tam bir kaynama meydana gelirse eklem dejenerasyonu önlenmiş olur veya geciktirilebilir. ${ }^{[9]}$ SDFG, semptomatik ve çökme gelişmemiş femur başı osteonekrozu olan 50 yaş altı hastalarda tedavi seçeneği olarak değerlendirilmektedir. ${ }^{[4,11]}$ Femur başı osteonekrozunun damarlı fibula ile tedavisinin başlangıçtaki çok iyi sonuçlarına rağmen 10 yılı aşan takiplerinde, kalça ekleminde artritik değişiklikler meydana gelebildiği bildirilmektedir. ${ }^{[4,9]}$ Eklem yüzeyinde 1-3 $\mathrm{mm}$ çökme olan femur başı osteonekrozlu hastalarda, serbest vaskülarize fibula grefti uygulaması, semptomları azaltır ve total kalça artroplastisinin

- Illetişim adresi: Prof. Dr. Kahraman Öztürk, Sağlık Bilimleri Üniversitesi Tıp Fakültesi, Ortopedi ve Travmatoloji Anabilim Dalı, El Cerrahisi Kliniği, İstanbul Tel: 0532 - 4271798 e-posta: kahraman_ozturk@hotmail.com

- Geliş tarihi: 6 Ey/ül 2020 Kabul tarihi: 23 Ey/ül 2020 

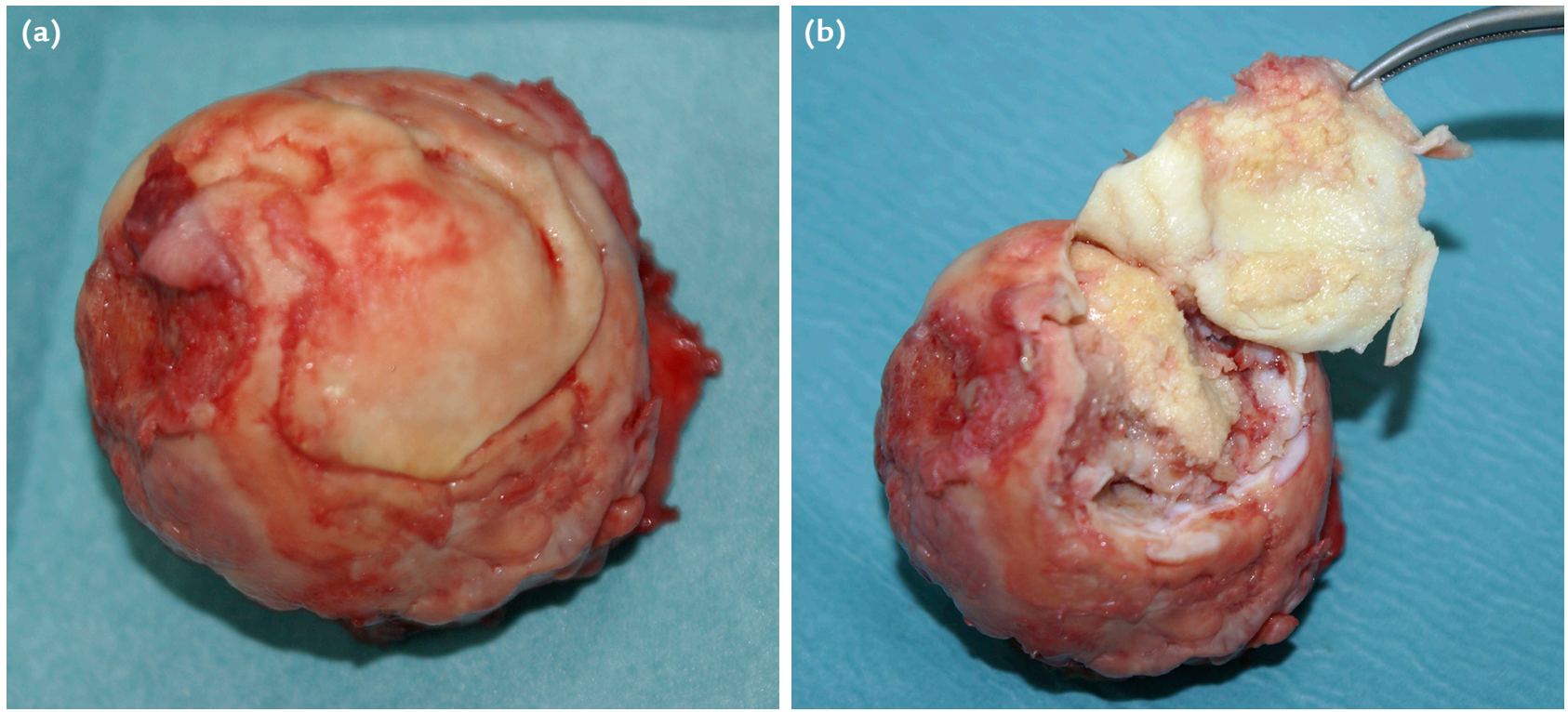

Şekil 1. a, b. Femur başı osteonekrozunda, başta çökme sonrası ileri derecede kıkırdak harabiyeti ile birlikte artroz gelişmiş femur başı (a) ve subkondral ayrışma (b) görülmektedir.

ertelenmesini sağlayabilir. ${ }^{[11]}$ Eş zamanlı steroid kullanımı damarlı fibula grefti ile tedavi yaklaşımı için bir kontrendikasyon değildir. ${ }^{\left[{ }^{5,8,9,12]}\right.}$ Fibula grefti damarsız şekilde de uygulanmaktadır. ${ }^{[13]}$ Femur başı osteonekrozu tedavisinde damarlı kemik grefti olarak kuadratus femoris kas pediküllü kemik gref$\mathrm{ti}^{\left[{ }^{14]}\right]}$ ve derin sirkumfleks iliak arter pediküllü iliak kemik grefti[ ${ }^{[15]}$ de kullanılmaktadır.

Serbest damarlı fibula grefti ile tedavide başarı ${ }^{[5,8,9,10]}$;

1. Hastalığın ilerlemesine yol açan iskemi ve kemik içi yüksek tansiyon döngüsünü kıran femur başının dekompresyonu,

2. Yeniden damarlanmayı engelleyebilen nekrotik kemik dokusunun çıkarılması,

3. Oluşturulan defektin osteoindüktif spongiyoz greft ve canlı kortikal kemikle doldurulması ile subkondral yüzeyin desteklenmesi ve revaskülarizasyon sürecinin hızlandırılması,

4. İyileşme döneminde bir süre ekstremiteye sınırlı yük verdirilmesine bağlanmıştır.

Total kalça artroplastisine (TKP) kıyasla damarlı fibular greftlemenin avantajları ${ }^{[4,5,8,9,10]}$ :

1. İyileşmiş bir femur başının varlığı daha fazla aktiviteye izin verebilir;

2. Yabancı cismin varlığına bağlı artmış risk yoktur;

3. İşlem, subkondral kırığın gelişmesinden önce uygulanabilinirse, hastaya yaşamı boyunca canlı bir femur başı sağkalımı sunabilir;
4. SDFG sonrası TKP ihtiyacı doğarsa, bu primer TKP sonrası revizyon artoplastisinden daha kolaydır.

Serbest damarlı fibula greftinin önerilmediği durumlar ${ }^{[4,5]}$;

1. Herhangi bir derecede semptomatik osteonekrozu olan 50 yaşından büyük hastalar,

2. 40 yaş üzeri ve ileri evre (evre IV) olgular,

3. Femur başı tutulumunun \%50'den fazla olduğu ve kalça hareketlerinde kısıtlanmayla birlikte olan hastalar,

4. Her iki alt ekstremitede vasküler kladikasyo belirtisi olan veya distal nabızların alınamadığı damar patolojisi olan hastalardır.

Osteoartritik değişiklikler mevcut olduğunda, total kalça protezi kaçınılmazdır. ${ }^{[10]}$ Total kalça artroplastilerinin \%10'u femur başı osteonekrozlu olgulara yapılmaktadır. [16]

Serbest damarlı fibula grefti uygulamanın dezavantajları;

- Deneyimli ekip gerektirmesi

- Floroskopi kullanılması

- Ameliyat süresinin uzunluğu

- Uzun iyileşme süresi

- Ancak genç ve uygun hastalarda yapılabilmesidir.

Femur başı avasküler nekrozunda (osteonekrozunda) idiyopatik veya alkole bağı osteonekroz 
hastalarının sonuçları daha kötüdür. ${ }^{[4,17]}$ Osteonekroz evresi, femurda baş tutulumunun yüzdesi ve etiyoloji, ilerlemeyi en çok belirleyen faktörlerdir. ${ }^{[13,17]}$ Yoo ve ark. ise, greft sağkalımının hastanın yaşı, lezyonun boyutu ve yeri ile ilişkili olduğunu ancak hastalığın etiyolojisi ve evresi ile ilişkili olmadığını bildirmiştir. ${ }^{[18]}$ Serbest damarlı fibula grefti ile tedavide, ameliyat öncesi femur başında çökme olması ve bilateral kalça tutulumunun olması sonuçları olumsuz etkilemektedir. ${ }^{[5,17,18,19]}$

\section{HASTA DEĞERLENDIRILMESI VE CERRAHI HAZIRLIK}

Hastaların ameliyat öncesi değerlendirilmesinde kalça, diz, ayak ve ayak bileği eklem hareket açıklığı, kas kuvvetleri ve duyu muayenesi yapılır. Popliteal, tibialis posterior ve dorsalis pedis arter nabızları palpe edilir ve kruris dolaşımı değerlendirilir. Ameliyat öncesi hazırlık için fibula alınacak tarafın kruris radyografisi, renkli Doppler ultrasonografi (US) ile popliteal bölgeden başlayarak damarsal trifurkasyon ayak bileğine kadar olan alanda değerlendirilir. Nabızlardan biri palpe edilemez veya Doppler US tetkikinde şüphe olursa anjiyografi yapilır.

Peroneal arter, \%90 tibialis posterior arterinden, $\% 1$ tibialis anterior arterinden, \%1 popliteal arterden çıkar. Alt ekstremiteyi \%8 oranında yalnızca tibialis posterior arteri beslemektedir. ${ }^{[20]}$

\section{Cerrahi Teknik}

Olguların tümü Urbaniak'ın tarif ettiği cerrahi metot izlenerek ${ }^{[11]}$ iki ekip tarafindan ameliyat edildi. Cerrahi işlem, Urbaniak'tan farklı olarak supin pozisyonunda kalça altına ince bir yükseklik koyularak yapıldı. Anestezi yöntemi olarak olguların çoğunda spinal anestezi ve çok azında genel anestezi kullanıldı. Her iki anestezi yöntemi de damar vazodilatasyonu ve ameliyat sonrası ağrı tedavisi için epidural anestezi ile birlikte uygulandı.

\section{Fibular greft alınması}

Ayak bileği stabilitesi için en az $7 \mathrm{~cm}$ fibula bırakacak şekilde alınması planlanan $15 \mathrm{~cm}$ fibula işaretlenir (Şekil 2a). Uyluğa steril turnike uygulanarak fibulanın hafif posteriorundan longitudinal $20 \mathrm{~cm}$ insizyon yapılır. Fasya longitudinal yönde kesilir (Şekil 2b). Periostun korunması için fibula üzerinde $1 \mathrm{~mm}$ kas doku bırakacak şekilde lateral kompartmanı oluşturan peroneal grup kaslar fibuladan ayırılır. Anterior intermusküler septum ortaya konur (Şekil 2c). Yeterli damar pedikül uzunluğu için diş malleol ucunun 10 $\mathrm{cm}$ proksimalinden başlayan $15 \mathrm{~cm}$ uzunlukta fibula işaretlenir. Alınacak fibulanın proksimal ve distalinden 5'er mm kemik parça çıkarılması, fibulanın rahat hareket ettirilmesi ile disseksiyonunu kolaylaştıracaktır. Fibula laterale doğru çekilerek anterior intermusküler septum longitudinal olarak kesilir. Anterior kompartman kasları, derin peroneal sinir ve anterior tibial arter korunarak künt disseksiyonla fibuladan sıyrılır ve interosseöz membran ortaya konur (Şekil 2d). Interosseöz membran longitudinal olarak fibuladan kesilerek ayırılır. Küçük perforatör damarlar kanamayı önlemek için, bipolar elektrokoter ve damar klipsleri ile kontrol edilir. Posterior intermusküler septum ayırılır, proksimalde soleus ve distal fleksör hallusis longus (FHL) kasları ortaya konur. Distalde peroneal damar paketi ortaya konur, ip veya damar klipsleri ile bağlanır ve kesilerek ayırılır. Serbest olan distal pedikül fibuladan ayrılmayı önlemek için fibulaya sutur veya damar klipsleri ile tespit edilir. Fibula ve bitişik peroneal damarlar, çevreleyen FHL, posterior tibial ve soleus kaslarından disseke edilir. Proksimalde kalan fibula eleve edilerek posteromedialde 4 ila $5 \mathrm{~cm}$ pedikül uzunluğu elde edilecek şekilde pedikül disseksiyonu yapılır (Şekil 2e). Turnike indirilir ve fibula dolaşımı kontrol edilir. Fibula ve kruris yumuşak dokusundan kaynaklanan kanamalar kontrol edilir. Posterior tibial damar paketinden çıkış noktasının hemen distalinde peroneal arter ve eşlik eden iki adet ven ayrı ayrı büyük damar klipsleri ile veya iple bağlanır ve kesilerek ayırılır. Fibular greft hazırlık için masaya alınır ve peroneal damar paketinden olacak sızıntıları engellemek için 1/100 oranında heparinli solüsyon ile arterden yıkama yapılarak kaçaklar kontrol edilir (Şekil 2f). Femur başına yerleştirilecek uç kısmında fibula periostu yaklaşık $10 \mathrm{~mm}$ kadar proksimale doğru sıyırılır ve dikilir. Fibula alınmış olmasına rağmen bacağın fasyal katmanları, kompartman sendromunun gelişmesini önlemek için yeniden yaklaştırılarak kapatılmaz. Dren konulur. Cilt ve cilt altı kapatıldıktan sonra distalden proksimale doğru sıkı olmayan elastik bandaj ile bacak sarılır.

\section{Kalça hazırlığı}

Spina iliaka anterior superior $10 \mathrm{~cm}$ distalinde lateral femoral sirkumfleks arter iz düşümü ve trokanter majör işaretlenir (Şekil 3a). Tepesi önde, 1/3'ü trokanter majörün üst tarafinda, kalanı alt tarafında olan yaklaşık $15 \mathrm{~cm}$ kavisli anterolateral insizyonla girilir. Trokanter majör arkasına kadar cilt ve cilt altı kanama kontrolü yapılarak kaldırılır (Şekil 3b). Tensor fasya lata tepesi trokanter majör arkasında olacak şekilde eğrisel $V$ şeklinde kesilir ve öne doğru kaldırılır (Şekil 3c). Lateral femoral sirkumfleks damar paketi ve ondan çıkan dallar rektus femoris öne, vastus intermedius arkaya çekilerek ortaya konur (Şekil 3d). Donör damarlar görüntülendiğinde, vastus lateralis ve intermedius başlangıcı trokanterik bölgeden dikkatli 

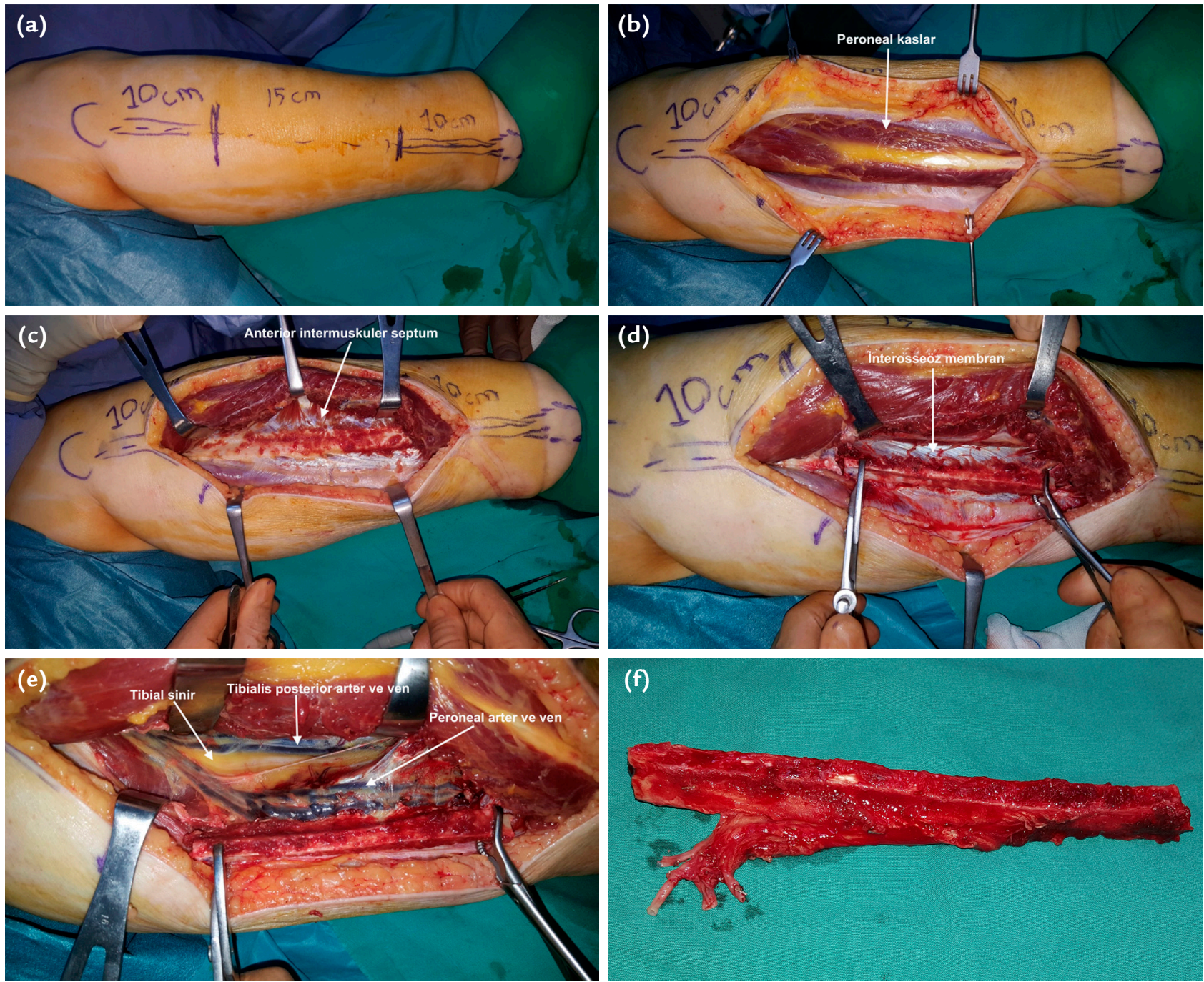

Şekil 2. a-f. Fibula disseksiyonu için lateral malleol proksimalinde $10 \mathrm{~cm}$ fibula bırakacak şekilde alınması planlanan $15 \mathrm{~cm}$ 'lik fibulanın proksimalde çizimi (a). Fibula üzerinde lateral ve posterior kompartman arasındaki sulkustan $20 \mathrm{~cm}$ longitudinal insizyon sonrası peroneal kasların görüntüsü (b). Fibula üzerinde periostu korumak için "marbleizing (mermere benzetme)" tekniği ile 1-2 mm'lik kas dokusu bırakılarak yapılan lateral kompartman disseksiyonu sonrası anterior intermusküler septum görülmektedir (c). Disseksiyonu kolaylaştırmak için fibula proksimal ve distalinden $5 \mathrm{~mm}$ kemik parça çıkarılması sonrası derin peroneal sinir ve tibialis anterior damar paketi korunarak anterior kompartman kaslarının interossseöz membrandan ayırılması (d). Fibula ve bitişik peroneal damarlar, kendilerini çevreleyen FHL, posterior tibial ve soleus kaslarından disseke edilir (e). Masaya alınan fibulada peroneal arter heparinli solüsyon ile yıkandıktan sonra arter ve venler disseke edilerek anastomoza hazır hale getirilir (f).

bir şekilde distale doğru tamamen kaldırılır. Görüşü artırmak için vastus lateralisin linea asperaya yapışan kalan lifleri ve rektus femoris arasına otomatik ekartör yerleştirilir. Lateral femoral sirkumfleks arter ve eşlik eden iki adet venin asendan dal disseksiyonu, büyüteç (loupe) veya cerrahi mikroskop büyütmesi altında yapılır. Yeterli pedikül uzunluğu için en az $4 \mathrm{~cm}$ olacak şekilde bir arter ve iki ven hazırlanarak etraf yumuşak dokudan disseke edilir ve anastomoz için hazırlanır. Otomatik ekartör çıkarılır. Vastus lateralisin posterior kısmı femurun proksimal posterolateral yüzünü ortaya koymak için linea asperadan yaklaşık 6-8 $\mathrm{cm}$ distale ve öne doğru sıyırılır. Kalça oyma işlemi için femurun proksimal kısmında vastus intermedius ve vastus lateralis kasları $\mathrm{S}$ elevatörle öne çekilir. C-kollu floroskop steril bir manşon ile örtülür ve kalça bölgesi üzerine yerleştirilir. Ön arka ve kurbağa bacağı floroskopi görünümü altında, manyetik rezonans (MR) görüntülemede tespit edilen nekrotik alanın merkezine, vastus sırtının $2 \mathrm{~cm}$ distali ve femur laterali orta 

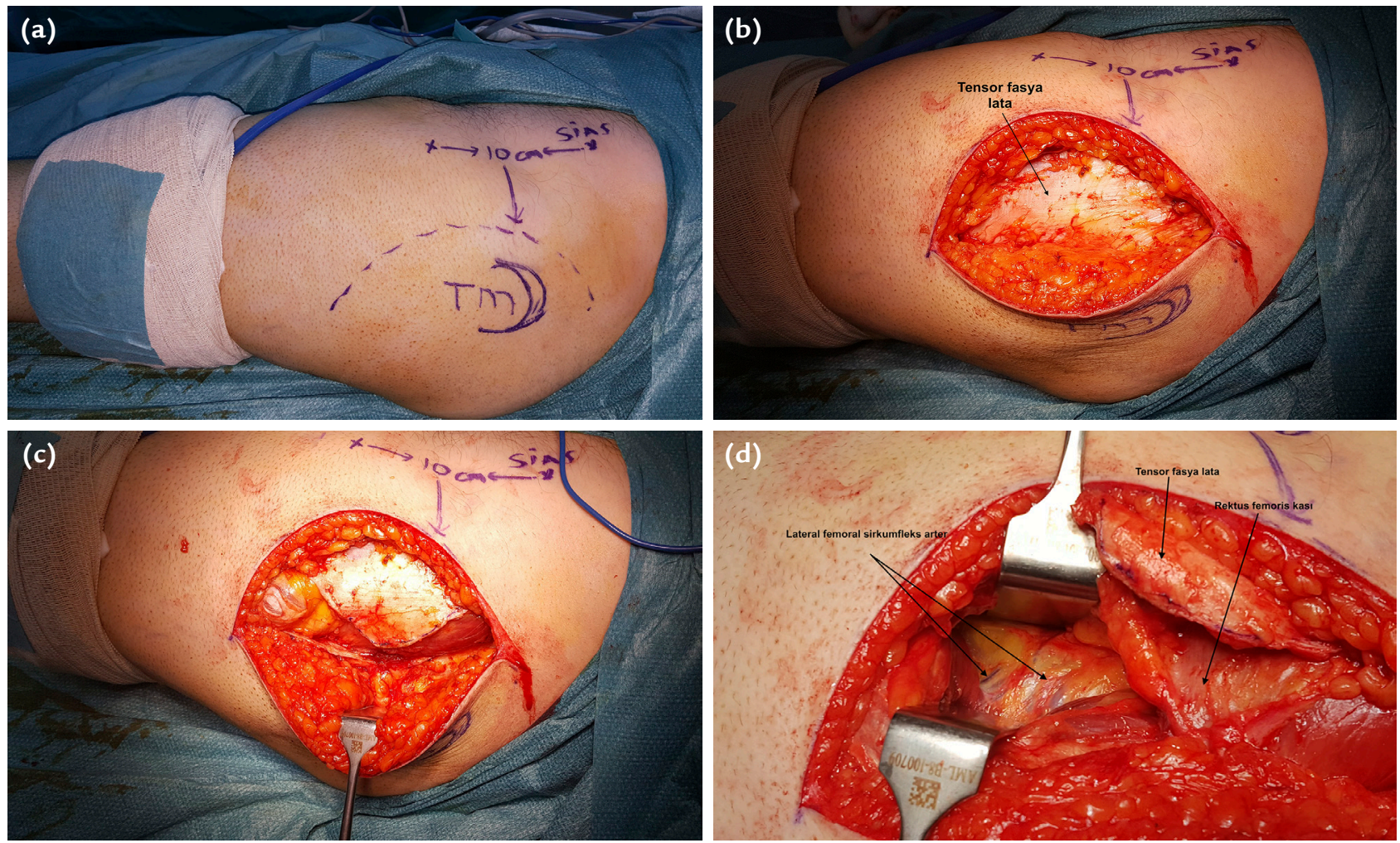

Şekil 3. a-d. Kalça cerrahisi için planlamada spina iliaka anterior superior $10 \mathrm{~cm}$ distali lateral femoral sirkumfleks arterin asendan dalının çıkış noktasını gösterir. Kubbe kısmı öne bakan $15 \mathrm{~cm}$ insizyon, proksimal üçte biri trokanterik bölgede vastus sırtının üst tarafında distal üçte biri ise alt tarafında olacak şekilde çizilir (a). Eğimli kısmı öne bakan cerrahi kesi sonrası cilt ve cilt altı arkaya doğru devirilen (b) hastada $\mathrm{V}$ şeklinde konveks tensor fasya lata kesisi (c). Vastus lateralis ve vastus intermedyus kasları arkaya rektus femoris kası öne doğru çekildikten sonra yağ yastığı altında lateral femoral sirkumfleks arter asendan dalı görülmektedir (d).

ve arka birleşim yerinden femur boynunu ortalayarak 3 mm'lik bir kılavuz Kirschner teli gönderilir. Kılavuz Kirschner teli femur başı anterosuperiorunda nekrotik alana yerleştirilir. Kılavuz Kirschner telinin yerleşimi ön arka ve kurbağa pozisyonunda lateral görüntü ile kontrol edilir (Şekil 4a, 4b). Oyma işleminden önce lateral femoral korteks delinerek trokanterik alandan süngerimsi greft elde edilir. Floroskopik ön arka ve kurbağa bacağı görüntü kontrolü altında femur başı çapları $10 \mathrm{~mm}$ ile başlayan ve fibula kalınlığına göre 22 mm'ye kadar artan oyucularla silindirik tünel şeklinde oyulur. Subkondral kollapsı ve femur başının delici ve oyucularla yaralanmasını önlemek için oyma, femur başında subkondral tabakanın 4 ila $5 \mathrm{~mm}$ altına kadar yapılır (Şekil 4c, 4d). Femur başı ve boynu, damarların sıkışmaması için fibula kalınlığından 2 $\mathrm{mm}$ daha büyük oyulur. Oyma sırasında çıkan sağlıklı kemikler greft olarak hazırlanır. Topuz uçlu bir oyucu ile subkondral nekrotik kemik alanı mantar başı gibi olacak şekilde debride edilir (Şekil 4e). Patolojik örnekler alınır. Oyulan alanın yeterliliği, femur başı içine suda çözünür kontrast madde verilerek floroskopi ile iki yönde de kontrol edilir (Şekil 4f, 4g). Tronkanterik bölgeden ve oyuculardan alınan süngerimsi greft femur başındaki subkondral alana yerleştirilir. Bu süngerimsi greftin ortası topuz uçlu oyucu ile ters yönde oyularak fibular grefte yer hazırlanır. Fibula grefti, damar pedikülü anterosuperiorda olacak şekilde posteriora doğru tünele yerleştirilir ve son pozisyonu floroskopi ile doğrulanır. Fibula 4,5 mm kanüllü titanyum vida ile uyluk kemiğine tespit edilir (Şekil 4h, 4i). Görüşü artırmak için vastus lateralisin linea asperaya yapışan kalan lifleri ve rektus femoris arasına otomatik ekartör yerleştirilir. Kanamayı önlemek için ilk olarak bir ven anastomozu yapılır. Daha sonra peroneal arter anastomozu yapılır. Ucu açık olan ve anastomoz yapılan peroneal venden venöz kan dönüşü değerlendirilir. Iikinci ven anastomozu yapılır (Şekil 5). Tüm damar anastomozları gerilim olmadan yapılmalıdır. Gerekirse alıcı toplardamarın Y şeklindeki uçları birleştirilerek peroneal ven ile arasındaki çap farkı ortadan kaldırılır. 

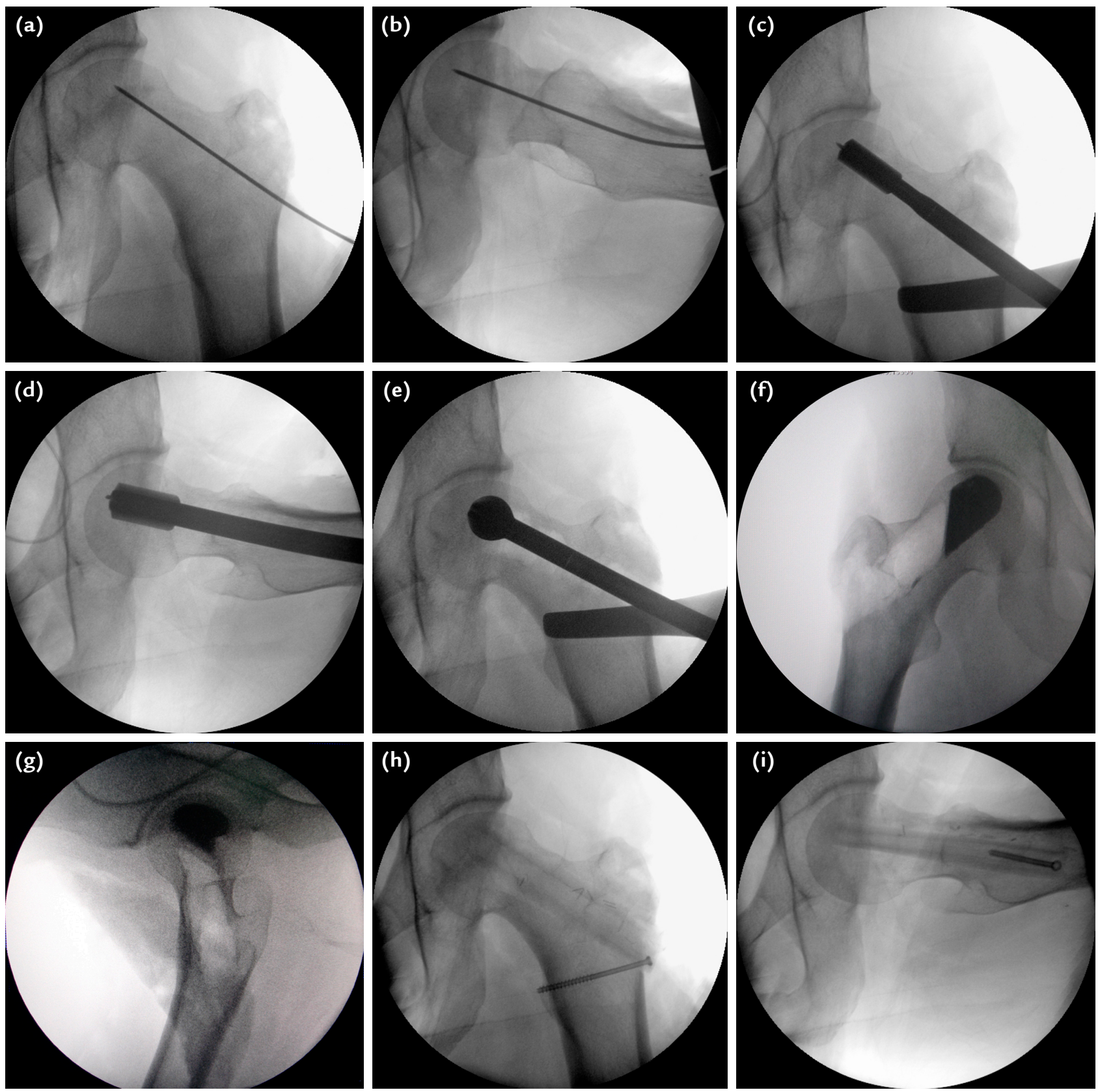

Şekil 4. a-i. Femur başında nekrotik alanın merkezine yerleştirilen Kirschner telinin ön arka (a) ve kurbağa bacağı pozisyonda floroskopi (b) görüntüleri. Femur başında gittikçe artan büyüklükte oyucularla yapılan oyma işleminin ön arka (c) ve kurbağa bacağı pozisyonunda floroskopi (d) görüntüleri. Topuz uçlu oyucu ile femur başı subkondral alanın boşaltılması (e). Suda eriyen kontrast madde verilerek femur başında oyma miktarının kontrolü ön arka (f) ve kurbağa bacağı pozisyonunda (g) floroskopi ile yapılır. Fibula yerleştirildikten sonra ön arka (h) ve kurbağa bacağı pozisyonunda (i) floroskopi ile fibulanın yerleşimi kontrol edilir.

\section{Ameliyat sonrası takip ${ }^{[11]}$}

Ameliyat sırasında damar anastomozları yapılacağı zaman başlanan $9 \mathrm{gr} \mathrm{NaCl}$ ve $10 \mathrm{gr}$ dekstrandan oluşan çözelti (rheomacrodex) $500 \mathrm{cc} /$ gün üç gün verilir. Ameliyat sonrası düşük molekül ağırlıklı heparin 21 gün, $300 \mathrm{mg}$ asetilsalisilik asit/gün 3 ay, ameliyat sonrası ağrı için ilk 48 saat $\% 0.5$ bupivakain ve $\% 2$ lidokain karışımı verilir. Ameliyat sonrası ikinci gün FHL germe egzersizleri başlanır, kalça, diz ve ayak bileği eklem hareket açıklığı ve kuvvetlendirme egzersizleri yaptırılır. Erken dönemde çift koltuk değneği ile ayağa kaldırılarak yürümesine izin verilir. Altıncı hafta, 3, 6, 


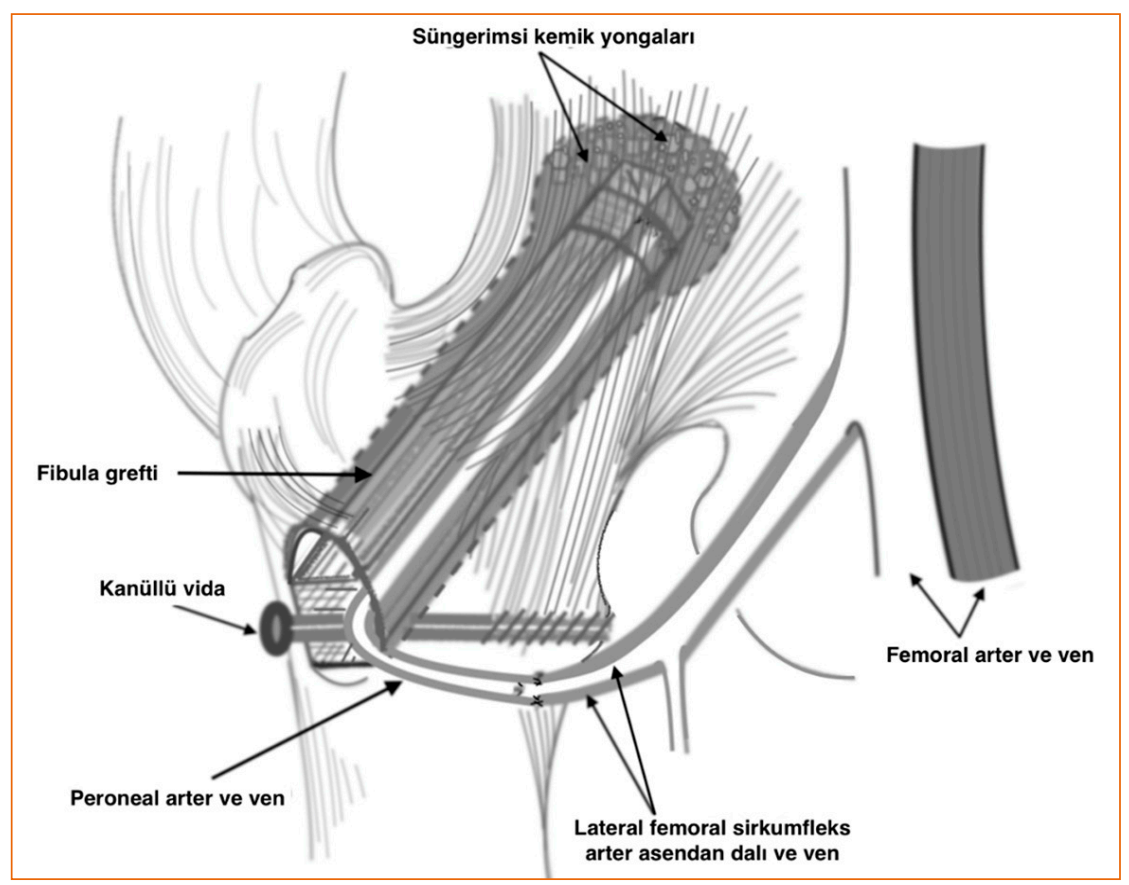

Şekil 5. Femur başında subkondral alana süngerimsi kemik yongaları yerleştirilir. Damarlı fibular greft femur başına açılan silindirik tünelden yerleştirilir ve kanüllü vida ile stabilize edilir. Peroneal venler ve arter, lateral femoral sirkumfleks arter ve venlerin asendan dallarına anastomoz edilir.

12,18 ve 24 ay sonunda klinik ve radyolojik kontrol takibi yapılır. Daha sonraki takipler yıllık kontrol şeklinde uygulanır (Şekil 6).

Ameliyat sonrası 3 ay sonunda kısmi, olguya göre 4-6 ayda tam yük verilir.

\section{Komplikasyonlar}

Damarlı fibula nakli ameliyatında en sık fibula alımına bağlı olarak komplikasyonlar ortaya çıkmaktadır. En sık görülen ve genelde geçici olan komplikasyonlar ayakta duyu kaybı ve motor zayıflıktır (peronal sinir traksiyonundan kaçınılarak önlenebilir). Ayak başparmak fleksiyon kontraktürünü önlemek için ameliyattan birkaç gün sonra germe egzersizleri başlanılmalıdır. Kontraktür kalıcı hale gelirse, FHL tendonuna Z plasti ile uzatma yapılır. Daha az oranda yüzeyel enfeksiyon, hematom ve tromboembolik komplikasyon görülebilir. Bazı hastalarda geç başlayan ayak bileği ve alt ekstremitede ağrı prevalansı zamanla artar. ${ }^{[18,21,22]}$ Spongiyoz kemik grefti almak için trokanterik bölgenin fazla boşaltılmasına bağlı subtrokanterik femur kırığı gelişebilir. Bu durum yalnızca trokanter majordan greft alınması ile \%1'in altına inmiştir. ${ }^{[5,18]}$ Bu kırıkların çoğu, ameliyat sonrası 6-8 haftalık dönemde kendini daha iyi hissetmeye başlayan hastanın ekstremitesine torsiyonel bir kuvvet uygulaması ile birlikte aşırı yük vermesi ile meydana gelir. Yine fibula yerleştirebilmek için femurun agressif debridmanına bağıı olarak da kırık meydana gelmektedir. ${ }^{[5,23,24]}$

\section{TARTIŞMA}

Femur başı avasküler nekrozunun (osteonekrozunun) çökme olmadan erken evrede tedavisi için kor dekompresyon, vaskülarize olmayan otolog kemik greftleri, gözenekli tantal implant prosedürü ve çeşitli eklem dışı osteotomiler uygulanmıştır. Bu tedavilerle tam anlamıyla etkili, öngörülebilir sonuçlar elde edilememiştir. ${ }^{[10]}$ Çökme olmamış femur başı osteonekrozunda SDFG'nin femur başında çökmenin önlenmesi ve kalça fonksiyonunun iyileştirilmesi için önemli bir tedavi seçeneği olduğu gösterilmiştir. ${ }^{[4,9,13,18,25]}$ Urbaniak ve ark., kor dekompresyon ve SDFG ile tedavi edilen 103 kalçanın 5 yıllık takibinde, evre II'de \%91, evre III'te \%77 sağkalım bildirmiştir. ${ }^{[26]}$ Yoo ve ark., evre II ve III osteonekrozu olan 124 kalçanın en az 10 yıllık takibinde \%89 sağkalım ile mükemmel sonuçlar elde etmiştir. ${ }^{[18]}$ Femur başında çökme olmadan nekrotik kemiğin uzaklaştırılması ve SDFG ile yapılan tedavi femur başında çökmeyi önler veya geciktirir. ${ }^{[4,25]}$ Hastaların \%81'i SDFG yaptırma kararından memnun olduğunu ve \%86'sı ağrı kesici ilaç ihtiyacında azalma olduğunu bildirmiştir. ${ }^{\left[{ }^{[5]}\right.}$

Kor dekompresyon, erken evre femur başı osteonekrozunda en sık uygulanan tedavi yöntemidir. ${ }^{[6,25]}$ Scully ve ark., serbest damarlı fibula grefti ile tedavi edilen ve 50 ay takibi olan Ficat evre II 111 kalçada \%89, evre III 500 kalçada \%81; kor dekompresyon ile tedavi edilen Ficat evre II 43 kalçada $\% 65$ ve evre III 47 kalçada ise \%21 başarılı sonuç bildirmiştir. ${ }^{[25]}$ Kor dekompresyon ile tedavi edilen femur başı osteonekrozu olan 

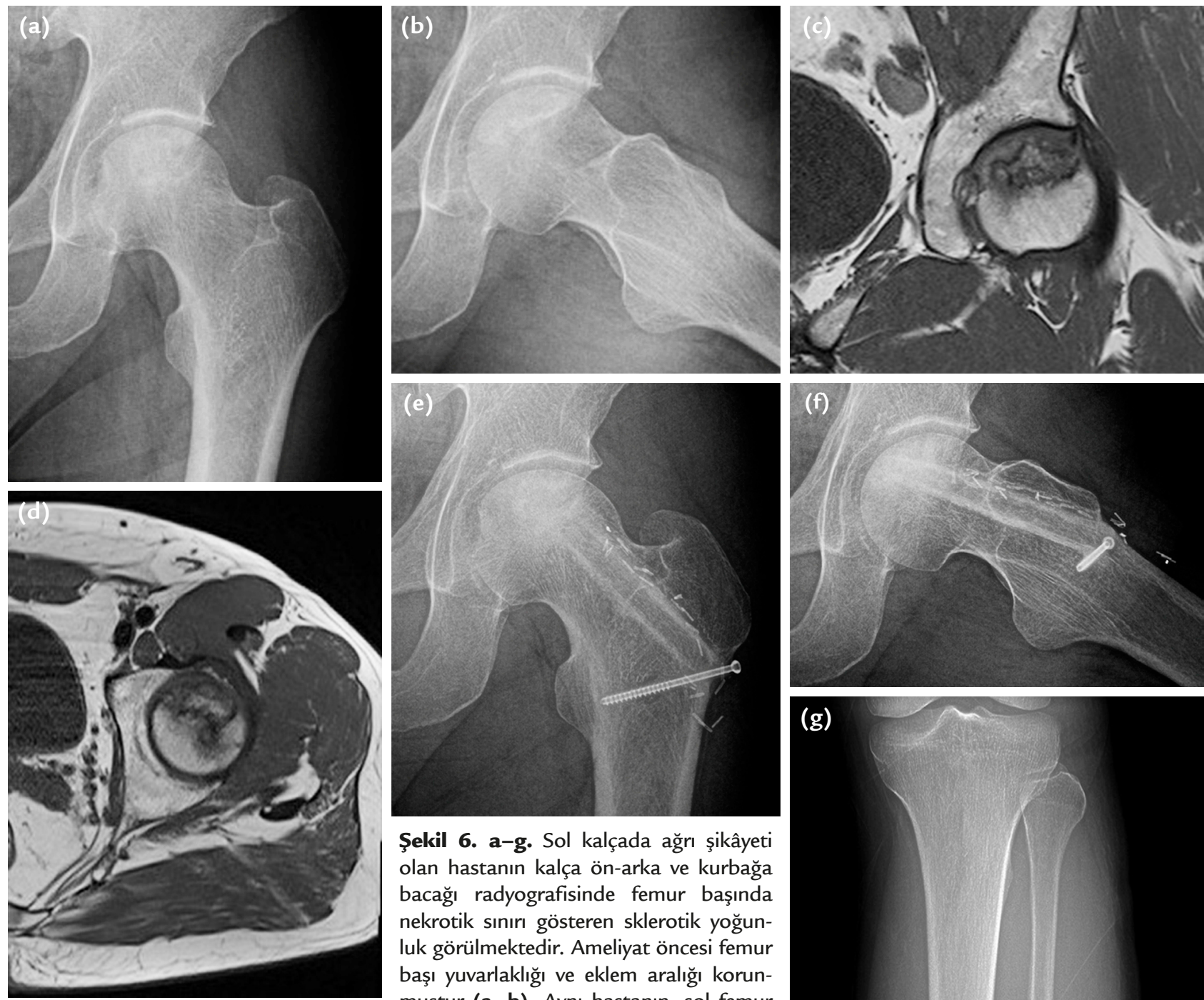

Şekil 6. a-g. Sol kalçada ağrı şikâyeti olan hastanın kalça ön-arka ve kurbağa bacağı radyografisinde femur başında nekrotik sınırı gösteren sklerotik yoğunluk görülmektedir. Ameliyat öncesi femur başı yuvarlaklığı ve eklem aralığı korunmuştur (a, b). Aynı hastanın, sol femur başının ağırık taşıyan üst kısmında canlı ve cansız kemik arasındaki patognomonik geçiş sınırını gösteren T1 ağırlıklı koronal ve aksiyel MR görüntüsü (c, d). Serbest damarlı fibula greftlemesinden 5 yıl sonra sol kalçada fibula grefti ile baş arasında tam kaynama olduğu görülmektedir. Femur başında çökme olmaksızın, femur baş yuvarlaklığı ve eklem aralığı korunmuştur (e, f). Fibula alınmış olan krurisin radyografisi (g).

hastalarda daha fazla radyografik ilerleme gözlenmiştir. Ficat evre-II-III hastalığı olan kalçalar arasında, damarlı fibular greftlemeden sonra nihai total eklem artroplastisi oranı, kor dekompresyona göre önemli ölçüde daha düşüktür. ${ }^{[6,25]}$

Judet ve Gilbert, femur başının eklemden çıkarılıp kıkırdağın kaldıılarak serbest damarlı fibulanın yerleştirilmesi ve greftleme sonuçlarının erken evre ve genç olgularda başarılı olduğunu bildirmiştir. Kalça eklem kapsülünün açılması sebebiyle eklem sertlik oranının yüksek olduğu 68 kalçada, 18 yıl sonunda $\% 52$ kalçada sağkalım sonucu bildirmişlerdir. ${ }^{[12]}$
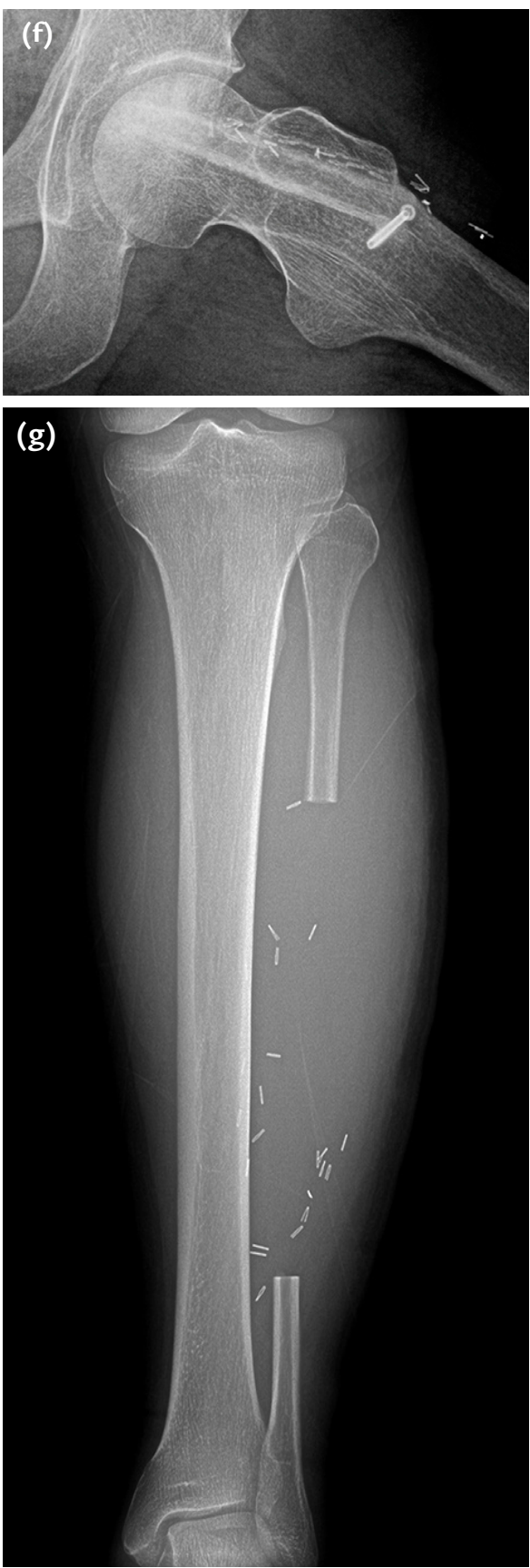
Plakseychuk ve ark., özellikleri ortak olan evre I ve II kalçaların 7 yıllık takipli iki seride damarsız uygulanan fibula grefti ile \%30 iyi, serbest damarlı fibula grefti ile \%86 iyi sonuç almıştır. ${ }^{[27]}$ SDFG ile tedavide radyografik ilerleme ve çökme oranları anlamlı olarak düşüktür. ${ }^{[13,27]}$

Lee ve Rahmetullah tarafindan, idiyopatik femur başı avasküler nekrozunun nekrotik alanın küretajı, süngerimsi kemik grefti ve kuadratus femoris kas pediküllü kemik grefti ile tedavi edildiği 10 olgu bildirilmiştir. Kırk iki ay izlemede birinde evre III'e ilerleme olan kalçaların 7'sinde başarılı sonuç alınmıştır. Küretaj, süngerimsi kemik grefti ve kuadratus femoris kas pediküllü kemik grefti ile tedavinin evre I ve II kalça avasküler nekrozunda başarılı olduğunu düşünmektedirler. ${ }^{[14]}$ Iwato ve ark., yüzeyel sirkumfleks iliak arter pediküllü iliak krest kemik grefti ile tedavi edilen 23 kalçanın 3'ünde bir yıl sonra evre III'e ilerleme tespit etmiştir. Üç yıl sonunda birinde $5 \mathrm{~mm}$. çökme olan 3 kalça evre III olarak kalmıştır. Diğer 20 kalçada evre III'e ilerleme olmuştur. ${ }^{[15]}$ Asmus, debridman ve damar pediküllü iliak kemik grefti uyguladığı ARCO evre II olguların \%25'inde avasküler nekrozda ilerleme bildirmiştir. Evre III olgularında ise femur başında çökme ve total kalça protezi gerekmiştir. ${ }^{[28]}$ Ayrıca uygulamada anatomiden kaynaklanan zorluk ve kalça eklem sertliği gibi damar pediküllü serbest fibula uygulamasına göre daha yüksek komplikasyon oranı olduğu kaydedilmiştir. ${ }^{[14,15,28]}$

Malizos ve ark., SDFG sonrası başarısız olan 16 femur başını ameliyattan ortalama 50 ay sonra total kalça protezi esnasında çıkararak incelemişler ve 14 kalçada peroneal arterden kan akımının devam ettiğini gördüklerini bildirmişlerdir. Yedi olguda yük verme alanında önemli kollaps, altı olguda femur başında tam harabiyet tespit etmiştir. 3 olguda ise eklem yüzeyinde çökme olmadan yük verme alanında küçük kist, kıkırdakta sertleşme ve yıpranma olduğu görülmüştür. Bazı hastalarda damarlı fibula grefti ile yeteri kadar kıkırdak beslenmesinin olmamasına rağmen, bu olguların çoğunda yeni kemik yapımı olduğunu tespit etmiştir. Asimetrik kemik iyileşmesi olması, yük taşıma alanında bulunan kıkırdak altında nekrotik kemikle greft arasında kaynama olmaması, başarısızlığa sebep olur ve erken total kalça protezi yapılması gerekir. ${ }^{[9]}$ Eward ve ark., fibula grefti sonrası ortalama takip süresi en az 10 yılı geçen prekollaps kalçalarda, total kalça artroplastisine dönüşüm öncesi kalça koruma süresinin ortalama 8,3 yıl olduğunu bildirmişlerdir. ${ }^{[4]}$ Malizos ve ark. ise, tam greft kaynaması sonrası nekrotik bölgelerde simetrik bir iyileşme elde edilse bile 8-10 yıl sonra kalça ekleminde artroplasti gerektirebilecek düzeyde bir artroz gelişebileceğini yazmışlardır. ${ }^{[9]}$
Aldridge ve ark., 4,3 yıl takip edilen femur başında kollaps gelişmiş fakat artrozu olmayan 188 olgunun 224 kalçasında \%63 iyi ve mükemmel sonuç almıştır. 73 kalçada ise total kalça artroplastisine dönülmüşsür. Eklem yüzeyinin çökmesi olan ileri osteonekrozlu hastalarda, serbest vaskülarize fibula grefti, semptomların uzun süreli azaltılması ve total kalça artroplastisinin ertelenmesini sağlayabilir. ${ }^{[11]}$

\section{KAYNAKLAR}

1. Lieberman JR, Berry DJ, Mont MA, Aaron RK, Callaghan JJ, Rayadhyaksha A, Urbaniak JR. Osteonecrosis of the hip: Management in the twenty-first century. J Bone Joint Surg Am 2002;84(5):834-53. Crossref

2. Petrigliano FA, Lieberman JR. Osteonecrosis of the hip: Novel approaches to evaluation and treatment. Clin Orthop Relat Res 2007;465:53-62. Crossref

3. Merle d'Aubigne R, Postel M, Mazabraud A, Massias P, Gueguen J. Idiopathic necrosis of the femoral head in adults. J Bone Joint Surg Br 1965;47-B(4):612-33. Crossref

4. Eward WC, Rineer CA, Urbaniak JR, Richard MJ, Ruch DS. The vascularized fibular graft in precollapse osteonecrosis. Is long-term hip preservation possible? Clin Orthop Relat Res 2012;470(10):2819-26. Crossref

5. Aldridge JM, Urbaniak JR. Avascular necrosis of the femoral head: role of vascularized bone grafts. Orthop Clin North Am 2007;38(1):13-22. Crossref

6. Fairbank AC, Bhatia D, Jinnah $\mathrm{RH}$, Hungerford DS. Long-term results of core decompression for ischaemic necrosis of the femoral head. J Bone Joint Surg Br 1995;77-B(1):42-9. Crossref

7. Sugioka Y, Hotokebuchi T, Tsutsui H. Transtrochanteric anterior rotational osteotomy for idiopathic and steroidinduced necrosis of the femoral head. Indications and longterm results. Clin Orthop Relat Res 1992;(277):111-20. Crossref

8. Soucacos PN, Beris AE, Malizos K, Koropilias, Zalavras $\mathrm{H}$, Dailiana Z. Treatment of avascular necrosis of the femoral head with vascularized fibular transplant. Clin Orthop Relat Res 2001;386:120-30. Crossref

9. Malizos KN, Quarles LD, Dailiana ZH, Rizk WS, Seaber AV, Urbaniak JR. Analysis of failures after vascularized fibular grafting in femoral head necrosis. Orthop Clin North Am 2004;35(3):305-14. Crossref

10. Korompilias AV, Beris AE, Lykissas MG, Kostas-Agnantis IP, Soucacos PN. Femoral head osteonecrosis: why choose free vascularized fibula grafting. Microsurgery 2011;31(3):223-8. Crossref

11. Aldridge JM 3rd, Berend KR, Gunneson EE, Urbaniak JR. Free vascularized fibular grafting for the treatment of postcollapse osteonecrosis of the femoral head: Surgical technique. J Bone Joint Surg Am 2004;86-A(Suppl 1):87-101. Crossref

12. Judet $H$, Gilbert $A$. Long-term results of free vascularized fibular grafting for femoral head necrosis. Clin Orthop Relat Res 2001;(386):114-9. Crossref

13. Kim S-Y, Kim Y-G, Kim P-T, Ihn J-C, Cho B-C, Koo K-H. Vascularized compared with non-vascularized fibular grafts for large osteonecrotic lesions of the femoral head. J Bone Joint Surg Am 2005;87(9):2012-18. Crossref

14. Lee CK, Rehmatullah N. Muscle-pedicle bone graft and cancellous bone graft for the "silent hip" of idiopathic ischemic necrosis of the femoral head in adults. Clin Orthop Relat Res 1981;(158):185-94. Crossref 
15. Iwato $H$, Torii S, Hasegqwa $Y$, Itoh H, Mizuno M, Genda E, Kataoka Y. Indications and results of vascularized pedicle iliac bone graft in avascular necrosis of the femoral head. Clin Orthop Relat Res 1993;295:281-8. Crossref

16. Mont MA, Hungerford DS. Non-traumatic avascular necrosis of the femoral head. J Bone Joint Surg Am 1995;77(3):45974. Crossref

17. Berend KR, Gunneson EE, Urbaniak JR. Free vascularized fibular grafting for the treatment of postcollapse osteonecrosis of the femoral head. J Bone Joint Surg Am 2003;85(6):98793. Crossref

18. Yoo MC, Kim KI, Hahn CS, Parvizi J. Long-term followup of vascularized fibular grafting for femoral head necrosis. Clin Orthop Relat Res 2008;466(5):1133-40. Crossref

19. Marcus ND, Enneking WF, Masam RA. The silent hip in idiopathic aseptic necrosis: treatment by bone grafting. J Bone Joint Surg Am 1973;55(7):1351-66. Crossref

20. Strauch B, Yu H-L, Chen $\mathrm{W}-\mathrm{Z}$, Liebling R. Atlas of Microvascular Surgery. Anatomy and Operative Approaches. Part two: Lower Extremity, 1st ed. New York: Thieme Medical Publishers; 1993. p.102-385.

21. Vail TP, Urbaniak JR. Donor-site morbidity with use of vascularized autogenous fibular grafts. J Bone Joint Surg Am 1996;78(2):204-11. Crossref

22. Gaskill TR, Urbaniak JR, Aldridge JM 3rd. Free vascularized fibular transfer for femoral head osteonecrosis: Graft and donor-site morbidity. J Bone Joint Surg Am 2009;91(8):18617. Crossref
23. Steinberg ME, Larcom PG, Strafford B, Hosick WB, Corces A, Bands RE, Hartman KE. Core decompression with bone grafting for osteonecrosis of the femoral head. Clin Orthop Relat Res 2001;(386):71-8. Crossref

24. Aluisio FV, Urbaniak JR. Proximal femur fractures after free vascularized fibular grafting to the hip. Clin Orthop Relat Res 1998;356:192-201. Crossref

25. Scully SP, Aaron RK, Urbaniak JR. Survival analysis of hips treated with core decompression or vascularized fibular grafting because of avascular necrosis. J Bone Joint Surg Am 1998;80(9):1270-5. Crossref

26. UrbaniakJR, Coogan PG, Gunneson EB, NunleyJA. Treatment of osteonecrosis of the femoral head with free vascularized fibular grafting. A long-term follow-up study of one hundred and three hips. J Bone Joint Surg Am 1995;77(5):681-94. Crossref

27. Plakseychuk AY, Kim SY, Park BC, Varitimidis SE, Rubash HE, Sotereanos DG. Vascularized compared with nonvascularized fibular grafting for the treatment of osteonecrosis of the femoral head. J Bone Joint Surg Am 2003;85(4):589-96. Crossref

28. Asmus A, Vogel K, Vogel A, Eichenauer F, Kim S, Eisenschenk A. Pedicled vascularized iliac bone graft for treatment of osteonecrosis of the femoral head. Oper Orthop Traumatol 2020;32(2):127-38. Crossref 